\title{
EFETIVAÇÃO JUDICIAL DO DIREITO À SAÚDE NO BRASIL: UMA BREVE REFLEXÃO À LUZ DO "MODELO DE DIREITOS FUNDAMENTAIS SOCIAIS" DE ROBERT ALEXY
}

\section{João Paulo de Souza Carneiro'}

Resumo: Hoje, o Poder Judiciário brasileiro está exercendo, de forma crescente, o papel de concretizador de direitos sociais. Essa postura é legitimada por um conjunto de ideias que pode ser nomeado como o "modelo teórico da utopia". O "modelo teórico da utopia" defende o "ativismo judicial" como forma de compensar a inércia dos demais poderes no cumprimento das promessas constitucionais na área social, e tem por característica marcante a despreocupação com a questão do custo dos direitos. Bem representativa dessa visão é a decisão proferida no julgamento da Petição 1.246 pelo ministro Celso de Mello, na qual se consignou que o direito à saúde deve prevalecer sobre interesses financeiros e secundários do Estado. Apesar do prestígio detido atualmente por essa forma de tratar a questão da efetivação dos direitos sociais, é oportuno revê-la na perspectiva do "modelo de direitos fundamentais sociais" de Robert Alexy. Ao defender a tese de que as normas de direitos fundamentais têm natureza principiológica, assegurando somente direitos prima facie que só se convertem em definitivos depois de um sopesamento com princípios colidentes, ele traça uma "resposta geral" para a determinação das posições prestacionais definitivas merecedoras de efeti-

1 Mestrando em Direito pela UFSC, especialista em Direito do Trabalho pela PUC/ PR, bacharel em Direito pela UFPR, Procurador do Estado de Santa Catarina. E-mail: jpcarneiro@pge.sc.gov.br 
vação na via judicial. $O$ "modelo de direitos fundamentais sociais" é compatível com o ordenamento jurídico brasileiro, podendo-se especular como seria apreciada judicialmente, com base nele, uma demanda relacionada ao direito à saúde.

Palavras-chave: Sopesamento. Alexy. Saúde. Direitos fundamentais.

\section{0 "MODELO TEÓRICO DA UTOPIA" E OS DIREITOS SOCIAIS}

A Constituição Federal de 1988 contém um extenso catálogo de direitos fundamentais. Dentro desse catálogo estão os direitos sociais, enumerados basicamente no art. $6^{\circ}$ da Carta Magna e posicionados no Título II, que trata "Dos direitos e garantias fundamentais", podendo-se falar, em nosso direito positivo, em "direitos fundamentais sociais":

Art. 6 São direitos sociais a educação, a saúde, a alimentação, o trabalho, a moradia, o lazer, a segurança, a previdência social, a proteção à maternidade e à infância, a assistência aos desamparados, na forma desta Constituição. (BRASIL, 2011, p. 32)

Parte respeitável da doutrina - senão a maioria - entende que os direitos sociais previstos na Constituição são plenamente exigiveis em juízo, independentemente da existência de legislação infraconstitucional, cabendo ao Poder Judiciário um papel ativo na sua efetivação e garantia. Esse posicionamento é claramente defendido por Luís Roberto Barroso, dentre outros doutrinadores: $[\ldots]$

De outras vezes, as normas constitucionais atributivas de direitos sociais:

(B) ensejam a exigibilidade de prestações positivas do Estado.

Aqui, ao contrário da hipótese anterior, o dever jurídico a ser cumprido consiste em uma atuação 
efetiva, na entrega de um bem ou na satisfação de um interesse. Na Constituição de 1988, são exemplos dessa espécie os direitos à proteção da saúde (art. 196), previdência social (arts. $6^{\circ}$ e 201), aposentadoria da mulher após trinta anos de contribuição (art. 201, § 7º, I). (BARROSO, 2000, p. 109)

Coerente com a sua ideia de que "O legislador constitucional é invariavelmente mais progressista que o legislador ordinário" (BARROSO, 1996, p. 260), o autor supramencionado chega a defender a possibilidade de fixação do valor do salário mínimo por via judicial, com a invalidação da lei que defina tal valor sem observar os requisitos insculpidos no art. 7º, IV, da Constituição:

Quid iuris, se o vício se contiver, não no ato em si do empregador, mas no do Congresso Nacional, por fixar um salário mínimo que desatenda os requisitos constitucionais? Em outras palavras: existe remédio jurídico a ser utilizado contra o ato legislativo que institua um salário mínimo incapaz de satisfazer as necessidades normais de um trabalhador e sua família?

A resposta é afirmativa. Tanto mais agora que o novo texto constitucional simplificou a tarefa jurisdicional ao estabelecer uma série de parâmetros objetivamente aferíveis. No regime da Carta de 1969, a cláusula "necessidades normais", sem qualquer outro detalhamento, padecia de um conteúdo fluido, algo impreciso, ainda que não indeterminável. Presentemente, todavia, o próprio inciso IV enuncia os fatores a serem tomados em conta na fixação do salário mínimo: moradia, alimentação, educação, saúde, lazer, vestuário, higiene, transporte e previdência social. E muito embora seja impossível erradicar-se totalmente um certo grau de subjetividade, é plenamente possível a um juiz, por dados oficiais ou mediante prova técnica, estimar, v.g., o valor de aluguel de uma habitação modesta em bairro operário, o custo de alimen- 
tação valorado por uma cesta básica, as despesas de transporte tendo em vista o preço da passagem etc. Mesmo quando os valores pudessem oscilar significativamente, de acordo com o que cada um viesse a considerar como padrão mínimo de dignidade, o fato é que há um núcleo central em relação ao qual haverá consenso em qualquer circunstância. (BARROSO, 2000, p. 151)

Nesse mesmo sentido, lembre-se o magistério de Paulo Bonavides, para quem "[...] os direitos fundamentais da segunda geração tendem a tornar-se tão justiciáveis quanto os da primeira" (2000, p. 518), e de Flávia Piovesan, que defende que "A ideia de não-acionabilidade dos direitos sociais é meramente ideológica e não científica" (2002, p. 240).

Dentro dessa ideia de plena e pronta exigibilidade dos direitos fundamentais sociais em juízo, independentemente da atuação do legislador - ou até mesmo contra essa atuação - caberia ao Poder Judiciário um papel de relevância. Dotando-se de uma postura "ativista", os juízes garantiriam a efetivação daqueles direitos, em prol da concretização da promessa constitucional, suprindo a omissão do legislador ou a inércia da sociedade civil. Como exemplo desse pensamento, cite-se trecho de obra de Andreas J. Krell:

Concordamos com Clève, que defende um novo tipo de Poder Judiciário e de compreensão da norma constitucional, com juízes "ativistas", vinculados às diretivas e às diretrizes materiais da constituição, voltados para a plena realização dos seus comandos e não apenas apegados aos esquemas da racionalidade formal e, por isso, muitas vezes simples guardiões do status quo. Torna-se necessária, portanto, uma "mudança de paradigmas" na percepção da sua própria posição e função no moderno Estado Social de Direito. (2002, p. 98)

Andreas J. Krell deixa claro que o juiz deve agir como uma "alavanca dinamizadora", forçando até mesmo a realização de direitos sociais cuja satisfação é considerada impossível: 
Esse tipo de ativismo judicial seria capaz, diante de cada situação e sem seguir receitas uniformes, de superar muitos dos óbices e representar uma "alavanca dinamizadora" para a realização dos direitos sociais postergados ou até "impossíveis", como tantas vezes denominamos aqueles que não são desfrutáveis por muitas pessoas sumidas na marginalidade, e os quais "podam a Democracia de um dos seus essenciais conteúdos”. (2002, p. 98)

A posição dos autores acima citados, que tende a ser hegemônica nos dias de hoje, pode ser resumida nos seguintes pontos: 1) os direitos sociais previstos na Constituição são direitos originários a prestações, cuja exigibilidade em juízo independe de legislação inferior; 2) o Poder Judiciário, baseado na autoridade da Constituição, deve ter uma atitude ativista em prol da concretização desses direitos. Pode-se chamar essa posição, com base no magistério de Flávio Galdino, de "modelo teórico da utopia” (2005, p. 186), cuja característica marcante é a abstração dos fatores extrajurídicos inerentes à realização dos direitos sociais.

Pelo "modelo teórico da utopia", o juiz ativista ater-se-ia ao que diz a Constituição, "levando os direitos a sério" e não se deixaria influenciar por questões estranhas ao plano meramente normativo, como aquelas relativas aos custos financeiros. Acerca disso, é interessante transcrever o seguinte trecho constante da obra "Introdução à teoria dos custos dos direitos":

Interessa salientar também, no plano conceitual, que os custos financeiros são vistos aqui como absolutamente externos ao conceito do direito, de tal sorte que o reconhecimento dos direitos subjetivos fundamentais precede e independe de qualquer análise relacionada às possibilidades reais de sua concretização (rectius: efetivação). Em síntese: o conceito e a eficácia dos direitos subjetivos especificamente considerados (v. g. direito à educação) são analisados em vista dos textos normativos, sem qualquer consideração concernente às possibili- 
dades reais de efetivação. (GALDINO, 2005, p. 187-188)

Curiosamente, os adeptos do "modelo teórico da utopia" adotam o mais puro normativismo kelseniano, muito embora digam seguir as trilhas da "Nova Hermenêutica" e do "neoconstitucionalismo". Assim como o juiz legalista pode ser acusado de insensibilidade social, o juiz ativista, na sua luta em concretizar a Constituição, pode ser acusado de insensibilidade financeira ou até mesmo institucional, pois não se importa com os impactos negativos das decisões tidas como realizadoras de direitos fundamentais sociais.

Apesar das críticas que lhe possam ser dirigidas, o "modelo teórico da utopia” tem uma grande influência no Poder Judiciário brasileiro, podendo-se dizer que uma parte importante senão a maioria - dos juízes o adota ao apreciar pedidos que envolvem os direitos fundamentais sociais previstos na Constituição. A aplicação do "modelo" é particularmente visível nos casos em que se pleiteia a satisfação do direito à saúde.

\section{UMA DECISÃO JUDICIAL PARADIGMÁTICA SOBRE O DIREITO À SAÚDE}

Sem dúvida alguma, dentre os direitos fundamentais sociais que estão sendo objeto de ações judiciais no Brasil sobreleva em importância o direito à saúde. Demandas judiciais pleiteando o fornecimento de medicamentos, a realização de cirurgias e exames e o fornecimento de aparelhos médicos tornaram-se corriqueiras.

Como fundamento de tais demandas, invoca-se, de forma genérica, o direito constitucional "à vida e à saúde". Ao apreciarem tais pedidos, os juízes geralmente aderem aos argumentos dos demandantes, retirando de dispositivos constitucionais de natureza principiológica direitos subjetivos praticamente ilimitados à prestação estatal. 
Um grande exemplo da adoção do "modelo teórico da utopia" no âmbito judicial - talvez o mais representativo - é a decisão proferida pelo ministro Celso de Mello, do Supremo Tribunal Federal, ao apreciar a Petição 1.246/SC, que vem servindo como paradigma para a apreciação de demandas relacionadas ao direito à saúde (SARLET; TIMM, 2008, p. 164).

O caso começou com a propositura de uma ação cautelar na qual se pleiteava, em face do Estado de Santa Catarina, o custeio de tratamento para a distrofia muscular de Duchenne em clínica norte-americana, no valor de US $\$ 63$ mil. O juízo de 1 o grau concedeu a liminar para que o Estado pagasse pelo tratamento, determinando, em seguida, o bloqueio de montante suficiente para tal depositado nas contas do ente público, e, subsequentemente, a sua transferência à mãe do autor. Essa decisão veio a ser confirmada em 2a instância, o que levou o Estado de Santa Catarina a pedir diretamente ao Supremo Tribunal Federal a sua suspensão.

O ministro Celso de Mello, então no exercício da Presidência da Corte, não concedeu a suspensão pleiteada, alinhavando basicamente os seguintes argumentos:

Entre proteger a inviolabilidade do direito à vida, que se qualifica como direito subjetivo inalienável assegurado pela própria Constituição da República (art. $5^{\circ}$, caput) ou fazer prevalecer, contra essa prerrogativa fundamental, um interesse financeiro e secundário do Estado, entendo - uma vez configurado esse dilema - que razões de ordem ético-jurídica impõe ao julgador uma só e possível opção: o respeito indeclinável à vida. (BRASIL, 1997)

No raciocínio desenvolvido pelo ministro Celso de Mello vislumbra-se como que uma ponderação: o direito à vida teria mais peso que o interesse financeiro do Estado. $\mathrm{O}$ ministro vem mantendo esse modo de ver a questão, como deixa claro em voto proferido no julgamento do Agravo Regimental em Suspensão de Tutela Antecipada 175, ocorrido em 17/03/2010: 
Tal como pude enfatizar em decisão por mim proferida no exercício da Presidência do Supremo Tribunal Federal, em contexto assemelhado ao da presente causa (Pet 1.246/SC), entre proteger a inviolabilidade do direito à vida e à saúde - que se qualifica como direito subjetivo inalienável a todos assegurado pela própria Constituição da República (art. 5, caput, e art. 196) - ou fazer prevalecer, contra essa prerrogativa fundamental, um interesse financeiro e secundário do Estado, entendo, uma vez configurado esse dilema, que razões de ordem ético-jurídica impõem, ao julgador, uma só e possível opção: aquela que privilegia o respeito indeclinável à vida e à saúde humana. (BRASIL, 2010)

Note-se que, nesse voto, Sua Excelência afirma que a Suprema Corte, como guardiã da Constituição, há que limitar a sua análise ao plano normativo, não lhe cabendo fazer considerações sobre eventuais limitações de recursos financeiros necessários à satisfação de direitos:

Essa relação dilemática, que se instaura na presente causa, conduz os Juízes deste Supremo Tribunal a proferir decisão que se projeta no contexto das denominadas "escolhas trágicas" (GUIDO CALABRESI e PHILIP BOBBITT, Tragic choices, 1978, W. W. Norton \& Company), que nada mais exprimem senão o estado de tensão dialética entre a necessidade estatal de tornar concretas e reais as ações e prestações de saúde em favor das pessoas, de um lado, e as dificuldades governamentais de viabilizar a alocação de recursos financeiros, sempre tão dramaticamente escassos, de outro.

Mas, como precedentemente acentuado, a missão institucional desta Suprema Corte, como guardiã da superioridade da Constituição da República, impõe, aos seus juízes, o compromisso de fazer prevalecer os direitos fundamentais da pessoa, dentre os quais avultam, por sua inegável precedência, o direito à vida e o direito à saúde. (BRASIL, 2010) 
As ideias defendidas pelo ministro Celso de Mello nos casos acima lembrados são perfeitamente enquadráveis no "modelo teórico da utopia", pois aliam o ativismo judicial concretizador de direitos constitucionalmente previstos a uma indiferença com as consequências das decisões judiciais que não digam respeito estritamente ao direito tutelado.

A estrutura argumentativa desenvolvida pelo ministro Celso de Mello e utilizada na apreciação da Petição 1.246 passou a inspirar grande parte - senão a maioria - das decisões judiciais exaradas em processos judiciais que tratam do direito à saúde. Em pesquisa no sítio do Tribunal de Justiça de Santa Catarina, encontraram-se pelo menos 125 precedentes jurisprudenciais que mencionam a decisão proferida na Petição 1.246 (TRIBUNAL DE JUSTIÇA DE SANTA CATARINA, 2012); no sítio do Tribunal de Justiça do Rio Grande do Sul, 173 precedentes (TRIBUNAL DE JUSTIÇA DO RIO GRANDE SO SUL, 2012); no do Tribunal de Justiça de Minas Gerais, 198 (TRIBUNAL DE JUSTIÇA DE MINAS GERAIS, 2012); já no sítio do Tribunal de Justiça de São Paulo há 2.557 precedentes que se referem àquela decisão (TRIBUNAL DE JUSTIÇA DE SÃO PAULO, 2012). Essa breve amostra é suficiente para demonstrar que, de fato, o entendimento adotado pelo ministro Celso de Mello no julgamento daquele caso vem servindo de referência para o Poder Judiciário.

Seguindo a trilha aberta pela decisão exarada na Petição 1.246, pode-se afirmar que parcela relevante do Poder Judiciário tende a considerar que: 1) o direito constitucional à saúde é um direito originário a prestações, que gera um correlato dever de o Estado proporcionar os meios hábeis à sua satisfação, sendo que sua eficácia provém diretamente da Constituição; 2) eventuais restrições orçamentárias, financeiras ou administrativas à concreção desse direito constituem fatores de menor relevância que devem ser ultrapassados em prol da concretização do programa constitucional por parte do juiz ativista. Em resumo: os juízes tendem a decidir que as normas constitucionais asse- 
curatórias do direito à saúde "têm maior peso" que as normas constitucionais que tratam da separação dos poderes, da lei orçamentária, do princípio da legalidade, etc.

A ideia que defende a prevalência do direito à saúde sobre interesses do Estado em toda e qualquer situação constitui uma expressão do "modelo teórico da utopia". Para se ver a questão sob outra perspectiva, é oportuno lembrar de outro modelo, o "modelo de direitos fundamentais sociais", proposto por Robert Alexy.

\section{0 "MODELO DE DIREITOS FUNDAMENTAIS SOCIAIS" DE ROBERT ALEXY}

A discussão acerca da efetivação do direito à saúde na via judicial é uma discussão acerca da exigibilidade dos direitos fundamentais previstos constitucionalmente. Por isso, é imprescindível abordar a forma de tratamento desses direitos dentro do sistema jurídico, a maneira como se deve lidar com eles. Para tanto, deve-se partir de um referencial teórico seguro e consagrado, e que seja compatível com o modelo constitucional brasileiro.

Uma obra de referência mundial sobre os direitos fundamentais é a "Teoria dos direitos fundamentais", de Robert Alexy, que, apesar de tratar da Constituição alemã, é uma lente gnoseológica adequada à compreensão da nossa própria Constituição. A “Teoria” apresenta a vantagem de estar centrada em aspectos deontológicos e normativos, valendo-se de uma argumentação racional prática que é extremamente conveniente para a resolução de problemas jurídicos (MENÉNDEZ; ERIKSEN, 2006, p. 1-12).

Robert Alexy parte da distinção entre regras e princípios. Para ele, "a distinção entre regras e princípios é uma das colunas mestras do edifício da teoria dos direitos fundamentais" (ALEXY, 2008, p. 85). Tanto as regras quanto os princípios são normas, mas enquanto as regras são aplicadas de acordo com o 
enunciado normativo oferecido pelo texto legal, os princípios são mandamentos de otimização, cujo cumprimento deve levar em consideração limites fáticos e jurídicos existentes (ALEXY, 2008, p. 90 e seguintes).

Segundo Alexy, os direitos fundamentais são dotados de uma natureza principiológica, não admitindo soluções na base do "tudo ou nada". Nessa linha, um direito fundamental assegurado pela Constituição é essencialmente prima facie, devendo submeter-se a um sopesamento com princípios constitucionais colidentes; caso o resultado dessa operação de sopesamento seja favorável ao direito fundamental, este de prima facie torna-se definitivo, consolidando-se como direito subjetivo exigível judicialmente. Saliente-se que não é possível, de antemão, prever se o direito fundamental prevalecerá sobre os princípios que lhe são contrapostos, pois devem ser consideradas as circunstâncias do caso concreto para se decidir qual princípio terá maior peso, formando-se, a partir delas, uma lei de colisão.

Esse brevíssimo resumo já é suficiente para demonstrar que a concepção de direitos fundamentais de Robert Alexy se choca com aquela professada pelos defensores do "modelo teórico da utopia”. O entendimento de que os direitos fundamentais têm natureza principiológica e que, por conta disso, estabelecem obrigações meramente prima facie, atenta para a necessidade de se considerarem fatores contrapostos para delimitar o âmbito do que é definitivamente exigível em juízo (justiciável). Isso é particularmente importante no caso dos direitos sociais, cuja concretização não pode prescindir de uma análise detida acerca dos custos envolvidos, pois, "nenhum direito cuja efetivação pressupõe um dispêndio seletivo de tributos pode, no final das contas, ser protegido unilateralmente pelo Judiciário sem considerar as consequências orçamentárias a serem suportadas por outras áreas do governo”2 (HOLMES e SUNSTEIN, 1999, p. 97).

2 No right whose enforcement pressupposes a selective expenditure of taxpayer contributions can, at the end of the day, be protected unilaterally by the judiciary without regard to budgetary consequences for which other branches of government bear the ultimate responsibility . (HOLMES e SUNSTEIN, 1999, p. 97) 
No capítulo 9 da "Teoria dos direitos fundamentais" Robert Alexy aborda claramente o problema dos direitos fundamentais sociais e propõe uma fórmula para identificar aqueles que seriam merecedores da tutela jurisdicional. De antemão, ele esclarece que "a questão acerca de quais direitos fundamentais sociais o indivíduo definitivamente tem é uma questão de sopesamento entre princípios" (ALEXY, 2008, p. 512). O seguinte trecho da "Teoria" resume em que consiste o "modelo de direitos fundamentais sociais":

O modelo não determina quais direitos fundamentais sociais definitivos o indivíduo tem. Mas ele diz que ele pode ter alguns e o que é relevante para sua existência e seu conteúdo. A resposta detalhada a essa questão é tarefa da dogmática de cada um dos direitos fundamentais sociais. Mesmo assim, é possível dar, aqui, uma resposta geral. Uma posição no âmbito dos direitos a prestações tem que ser vista como definitivamente garantida se (1) o princípio da liberdade fática a exigir de forma premente e se (2) o princípio da separação de poderes e o princípio democrático (que inclui a competência orçamentária do parlamento) bem como (3) os princípios materiais colidentes (especialmente aqueles que dizem respeito à liberdade jurídica de outrem) forem afetados em uma medida relativamente pequena pela garantia constitucional da posição prestacional e pelas decisões do tribunal constitucional que a levarem em consideração. Essas condições são necessariamente satisfeitas no caso dos direitos fundamentais sociais mínimos, ou seja, por exemplo, pelos direitos a um mínimo existencial, a uma moradia simples, à educação fundamental e média, à educação profissionalizante e a um patamar mínimo de assistência médica. (ALEXY, 2008, p. 512)

Em outras palavras: de acordo com a "resposta geral" sugerida por Alexy, o direito fundamental social definitivo é aquele que é essencial à promoção da liberdade fática (1) e que pode ser 
garantido sem afetar seriamente princípios colidentes, como o princípio da separação dos poderes, o princípio democrático e princípios concernentes a direitos de terceiros (2). Logo, em face de uma demanda embasada em um direito fundamental social previsto constitucionalmente, o Poder Judiciário deve fazer uma operação de sopesamento, para extrair do direito prima facie o direito definitivo, este sim objeto de concretização na via jurisdicional.

A imprescindibilidade da operação de sopesamento como forma de identificação do direito definitivo a ser tutelado judicialmente fica bem marcada por Alexy no seguinte trecho de sua obra:

A competência do tribunal termina nos limites do definitivamente devido. Mas os princípios contêm exigências normativas endereçadas ao legislador mesmo além desses limites. Um legislador que satisfaça princípios de direitos fundamentais além do âmbito do definitivamente devido satisfaz normas de direitos fundamentais mesmo se não está definitivamente obrigado a fazê-lo, e, por isso, não pode ser obrigado a tanto por um tribunal constitucional. (ALEXY, 2008, p. 519)

Seguindo o raciocínio de Alexy, pode-se distinguir um direito fundamental social vasto e rarefeito (prima facie) cuja submissão ao sopesamento com princípios colidentes dará como resultado um direito fundamental social menor e mais denso (definitivo); este último é concretizável judicialmente, ao passo que aqueloutro, não. Uma distinção parecida foi desenvolvida por Ricardo Lobo Torres, que propõe o recorte entre direitos fundamentais sociais, concernentes ao atendimento do mínimo existencial e hauridos diretamente da Constituição, e direitos sociais, cuja implementação caberia aos órgãos legislativos. (TORRES, 2009, p. 80-81).

O "modelo de direitos fundamentais sociais" de Robert Alexy preconiza o sopesamento como elemento chave para a 
determinação dos direitos prestacionais merecedores da tutela jurisdicional. Pode-se dizer que enquanto o "modelo teórico da utopia" seria seguido pelo juiz "ativista", o modelo de Alexy seria seguido pelo juiz "ponderador". Parece interessante refletir sobre a aplicação deste último modelo na apreciação judicial de casos relacionados ao direito à saúde, mas não sem antes verificar a sua compatibilidade com o ordenamento brasileiro.

\section{COMPATIBILIDADE DO “MODELO DE DIREITOS FUNDAMENTAIS SOCIAIS" COM O ORDENAMENTO BRASILEIRO}

A pedra de toque do "modelo de direitos fundamentais sociais" de Robert Alexy é a ideia de sopesamento, como operação pela qual se extraem direitos definitivos de direitos prima facie. Isso é coerente com o que o autor defende em relação aos direitos de defesa (ALEXY, 2008, p. 164, 465), o que demonstra que ele não trata de forma diferenciada os diversos tipos de direitos fundamentais.

Como dito acima, segundo Alexy uma posição no âmbito dos direitos a prestações tem que ser vista como definitivamente garantida se for exigida de forma premente pelo princípio da liberdade fática (1) e se não afetar de forma grave o princípio da separação de poderes, o princípio democrático e outros princípios materiais colidentes (2). Pois bem: é preciso verificar se esse parâmetro para identificação de um direito fundamental social definitivo é compativel com o ordenamento brasileiro.

Primeira e principalmente, centre-se a atenção no princípio da liberdade fática que, no "modelo de direitos fundamentais sociais", militaria em favor da efetivação do direito. Para entendê-lo melhor, lembre-se o conceito de liberdade fática elaborado pelo próprio Robert Alexy:

Apoiando-se e, ao mesmo tempo, apartando-se do conceito de liberdade jurídica é possível construir um conceito de liberdade fática, o qual tem espe- 
cial importância para as análises jurídicas, como um conceito contraposto ao conceito de liberdade jurídica:

(4) Em relação a uma alternativa de ação juridicamente livre, $a$ é faticamente livre na medida em que tem a possibilidade real de fazer ou deixar de fazer aquilo que é permitido. (ALEXY, 2008, p. 226)

A liberdade fática pode ser vista, portanto, como a possibilidade real de exercício das liberdades jurídicas, e, por isso, está diretamente relacionada à ideia de direitos fundamentais. Constatar essa ligação não implica necessariamente a adesão a um ideário liberal, pois a liberdade é o fator que proporciona as condições sociais para a realização da dignidade do homem, objetivo de toda concepção jurídica respeitável. A igualdade, nessa linha, seria um complemento da liberdade em prol da universalização deste último valor.

Vejam-se, sobre isso, as lições de Gregorio Peces-Barba Martínez:

Se estipulamos um sentido, podemos entender como fundamento dos direitos aquelas razões morais, que derivam da dignidade do homem e que são condições sociais da realização da mesma, é dizer, sem cuja presença na vida social as pessoas não podem desenvolver todas as virtualidades nela insertas. Para identificá-las teríamos que utilizar os materiais proporcionados na análise diacrônica, e integrá-los em uma reflexão racional, que pusesse em relevo esses valores e sua capacidade para abrir-se a dimensões políticas e jurídicas.

Tanto da análise histórica como da reflexão teórica, o primeiro valor que aparece por sua importância é o da liberdade, que encontramos em muitos discursos doutrinais desde o humanismo e o jusnaturalismo racionalista, com raízes tão antigas quanto o pensamento humano, e que cumpriria o papel, a meu juízo de valor central, do que derivam e se explicam outros, por sua maior 
proximidade com a ideia mesma de moralidade. Com efeito, não é descabido sustentar, e entre as contribuições históricas essa argumentação aparece reiteradamente, que alcançar a liberdade moral, sinônimo de autonomia e de independência, com respeito aos demais, na realidade social, cultural, econômica e política, é o fim da vida humana. $\mathrm{O}$ centro do consenso dos direitos será encontrar uma liberdade social e jurídica que facilite o que temos chamado de liberdade moral. Nas origens dos direitos, a tolerância tende a proteger a liberdade de consciência, e inclusive direitos tão específicos como as garantias processuais têm como objetivo último a liberdade. Desde esta se justifica a igualdade que, desde o meu ponto de vista, seria um complemento da liberdade, ao pretender a generalização deste valor para que todos possam ser realmente livres na vida social. ${ }^{3}$ (MARTÍNEZ, 1999, p. 209-210, tradução nossa)

Resta saber se a subordinação (ou conexão) da ideia de direitos fundamentais sociais com o princípio da liberdade fática seria algo apropriado ao ordenamento jurídico brasileiro.

3 Si estipulamos un sentido, podemos entender como fundamento de los derechos aquellas razones morales, que derivan de la dignidad del hombre y que son condiciones sociales de la realización de la misma, es decir, sin cuya presencia en la vida social las personas no pueden desarrollar todas las virtualidades insertas en ella. Para identificarlas tendríamos que utilizar los materiales proporcionados en el análisis diacrónico, e integrarlos en una reflexión racional, que pusiese de relieve esos valores y su capacidad para abrirse a dimensiones políticas y jurídicas.

Tanto del análisis histórico como de la reflexión teórica, el primer valor que aparece por su importancia es el de la libertad, que encontramos en muchos discursos doctrinales desde el humanismo y el iusnaturalismo racionalista, con raíces tan antiguas como el pensamiento humano, y que cumpliría el papel, a mi juicio de valor central, del que derivan y se explican otros, por su mayor proximidad con la misma ideia de moralidad. En efecto, no es descabellado sostener, y entre las aportaciones históricas esa argumentación aparece reiteradamente, que alcanzar la libertad moral, sinónimo de autonomía y de independencia, respecto a los demás, en la realidad social, cultural, económica y política, es el fin de la vida humana. El centro de consenso de los derechos será encontrar una libertad social y jurídica que facilite la que hemos llamados libertad moral. En los orígenes de los derechos, la tolerancia tiende a proteger a la libertad de conciencia, e incluso, derechos tan específicos como las garantías procesales tienen como objetivo último la libertad. Desde ella se justifica la igualdad que, desde mi punto de vista, sería un complemento de la libertad, en cuanto pretende la generalización de ese valor para que todos puedan ser realmente libres en la vida social. (MARTíNEZ, 1999, p. 209-210) 
Uma objeção possível seria a de que esse entendimento reduziria indevidamente a extensão dos direitos fundamentais sociais, lembrando-se que o modelo proposto por Alexy foi pensado para a Alemanha, onde, ao contrário do Brasil, praticamente não há direitos sociais assegurados constitucionalmente (ALEXY, 2008, p. 500). Em outras palavras: no Brasil não haveria necessidade de buscar apoio para os direitos fundamentais sociais no princípio da liberdade fática, já que eles estão expressos na Carta Magna.

Ora, essa objeção pode ser rebatida com certa facilidade. Muito embora haja, na nossa Constituição, dispositivos que tratam de direitos sociais, não é possível inferir, a partir deles, as prestações que lhes seriam correspondentes. Na verdade, tais dispositivos são legítimos "conceitos abertos" carentes de uma interpretação determinadora de seu conteúdo. Como bem observa Ingo Sarlet:

A dificuldade de se definir, já em nível constitucional, com certa precisão o próprio objeto da prestação é, sem dúvida, outro aspecto correlato que aqui não pode ser desconsiderado, ao menos no que diz com boa parte dos direitos sociais a prestações. Basta que se faça menção aos exemplos do direito à saúde, ao trabalho e à educação para se notar a pertinência da consideração. (SARLET, 2011, p. 290)

Logo, tomar o princípio da liberdade fática como baliza para determinar o conteúdo de uma norma de direito fundamental social não é incompatível com o ordenamento brasileiro, e sim uma postura legítima na tarefa de demarcar o objeto de tutela da norma constitucional. Essa compatibilidade se torna ainda mais visível ao se lembrar que a liberdade fática tem um vínculo estreito com a dignidade da pessoa humana, valor fundante de nosso sistema jurídico (art. 1º, III, da Constituição).

Agora, cabe analisar a possibilidade de se considerarem o princípio da separação dos poderes, o princípio democrático e 
outros princípios materiais colidentes como contra-argumentos à efetivação de um direito fundamental social.

$\mathrm{Na}$ verdade, essa tarefa não oferece nenhuma dificuldade. Por óbvio, tais princípios podem ser levados em conta para definir uma posição prestacional definitivamente garantida se estiverem previstos na Constituição de forma explícita ou implícita, condição que é satisfeita pelo princípio da separação dos poderes (art. 20 e art. 60, § 4, III, da Constituição) e pelo princípio democrático (art. 1º caput e $\S$ único, art. 14, art. 59, art. $60, \S 4^{\circ}$, II, etc.). Igual condição deve ser satisfeita pelos "princípios materiais colidentes" a serem invocados no caso concreto.

Diante disso, nota-se que o "modelo de direitos fundamentais sociais" proposto por Robert Alexy em sua "Teoria dos direitos fundamentais" é compatível com o ordenamento jurídico brasileiro. A partir dessa conclusão, pode-se especular como seria apreciada uma demanda judicial relacionada ao direito à saúde no Brasil, tendo em vista os princípios favoráveis e contrários à efetivação de um direito fundamental social.

\section{UM EXERCÍCIO DE APLICAÇÃO DO “MODELO DE DIREITOS FUNDAMENTAIS SOCIAIS"}

Como já visto aqui, há uma grande influência do "modelo teórico da utopia” sobre o Poder Judiciário. Juízes "ativistas" extraem da Constituição direitos sociais prontos e acabados, praticamente ilimitados, sem contrastar de maneira adequada os argumentos favoráveis à realização desses direitos com os argumentos desfavoráveis.

Já foi dito também que uma decisão muito representativa do "modelo teórico da utopia" é aquela tomada na apreciação da Petição 1.246 pelo ministro Celso de Mello, do Supremo Tribunal Federal. $\mathrm{O}$ argumento utilizado pelo ministro para negar o pedido do Estado de Santa Catarina foi, em suma, o seguinte: o direito à vida prevalece sobre "interesses financeiros e secundários do Estado" - note-se que tais interesses são apenas 
mencionados sem que se os coloque como fatores dignos de tutela.

Com base no precedente firmado na Petição 1.246, foram prolatadas diversas decisões. Uma delas é o acórdão prolatado pelo Tribunal de Justiça de São Paulo em 29 de agosto de 2011, no julgamento dos Embargos Infringentes no 0000340 0000899-39.2007.8.26.0491/50000, opostos pelo Município de Rancharia contra decisão que lhe tinha imposto a obrigação de fornecer bomba infusora de insulina a portadora de diabetes. $\mathrm{O}$ acórdão está assim ementado:

EMBARGOS INFRINGENTES - Recurso com apoio em voto minoritário - Obrigação de fazer Fornecimento de bomba infusora de insulina para portadora de Diabetes Mellitus - Laudo médico e perícia atestando a necessidade da bomba para o tratamento da autora - Concretização do direito à vida e à saúde, cabendo ao Estado propiciar o atendimento médico, fornecendo o insumo prescrito - É necessário que esse direito venha a ser respeitado e implementado pelo Estado, destinatário do comando Constitucional - Recurso não provido. (SÃO PAULO, 2011)

O Tribunal de Justiça de São Paulo decidiu que o Município de Rancharia tinha a obrigação de fornecer a bomba infusora de insulina à autora, portadora de diabetes, fazendo menção expressa a precedente em que se cita a Petição 1.246:

Bem por isso, o art. 196 da Constituição Federal reconhece que a saúde é direito de todos e obrigação do Estado, que promoverá o atendimento integral do indivíduo, abrangendo a promoção, preservação e recuperação de sua saúde.

Longe de se ver aqui normas programáticas, recurso pelos quais usualmente os administradores públicos se escusam de cumprir as obrigações que lhes são dirigidas pela Constituição Federal, há que se ver normas impositivas de eficácia plena, que 
objetiva (sic) tornar real e não meramente retórico o direito à vida proclamado no art. 5o da Constituição Federal.

O eminente ministro Celso de Mello em primoroso voto proferido no julgamento do RE 267.612RS, deixou consignado:

"Na realidade, o cumprimento do dever político-constitucional consagrado no art. 196 da Lei Fundamental do Estado, consistente na obrigação de assegurar, a todos, a proteção à saúde, representa fator, que, associado a um imperativo de solidariedade social, impõe-se ao Poder Público, qualquer que seja a dimensão institucional em que atue no plano de nossa organização federativa.

A impostergabilidade da efetivação desse dever constitucional desautoriza o acolhimento do pleito recursal ora deduzido na presente causa.

Tal como pude enfatizar, em decisão por mim proferida no exercício da Presidência do Supremo Tribunal Federal, em contexto assemelhado ao da presente causa (Pet 1.246-SC), entre proteger a inviolabilidade do direito à vida e à saúde, que se qualifica como direito subjetivo inalienável assegurado a todos pela própria Constituição da República (art. 5, caput e art. 196), ou fazer prevalecer, contra essa prerrogativa fundamental, um interesse financeiro e secundário do Estado, entendo - uma vez configurado esse dilema - que razões de ordem ético-juridica impõem ao julgador uma só e possível opção: aquela que privilegia o respeito indeclinável à vida e à saúde humana, notadamente daqueles, como os ora recorridos, que têm acesso, por força da legislação local, ao programa de distribuição gratuita de medicamentos em favor de pessoas carentes. [...]" (SÃO PAULO, 2011)

Seguindo a linha de pensamento do "modelo teórico da utopia" e o seu notório desprezo pela questão do custo dos direitos, o Tribunal de Justiça de São Paulo achou por bem admoestar duramente o ente público, afirmando que a impossibilidade orçamentária era um argumento destituído de significação: 
A Municipalidade de Rancharia não compreendeu bem, o que é profundamente lamentável, que o que está em causa é o direito à vida, bem supremo que é tutelado constitucionalmente.

Não é suficiente, portanto, que o Estado proclame o reconhecimento de um direito Constitucional, para solapá-lo por meio de gestões de duvidosa eficiência e moralidade. É necessário que esses direitos venham a ser respeitados e implementados pelo Estado, destinatário do comando Constitucional.

Se não o fez, se pretexta a retórica com argumentos destituídos de significação, como a impossibilidade orçamentária, assiste ao cidadão o direito de exigir do Estado a implementação de tais direitos. (SÃO PAULO, 2011)

\section{O Tribunal ainda lança conselhos de boa administração} pública e vitupera algumas práticas que considera condenáveis:

O argumento tão ao gosto dos burocratas de que o reconhecimento desse direito essencial ao cidadão do acesso à saúde, pode implicar em comprometimento de outras políticas públicas de saúde não prevalece.

Basta se proceda (sic) a uma gestão racional, eficiente e honesta da coisa pública. Que não se socorra com dinheiro público grandes conglomerados econômicos, que não se venda dólares a preços subsidiados a banqueiros falidos, em afronta ao princípio da legalidade e da moralidade administrativa. Que se faça, enfim, a devida aplicação da contribuição tributária sobre movimentação financeira destinada aos programas de saúde pública.

Se o estado não atingiu, ainda, o grau ético necessário a compreender essa questão, deve ser compelido pelo Poder Judiciário, guardião da Constituição, a fazê-lo. (SÃO PAULO, 2011) 
O acórdão aqui analisado é bem representativo da postura do "juiz ativista", que entende que a falta de efetividade dos direitos constitucionais é culpa de um Estado alheio ao cumprimento de suas funções.

Pense-se agora na forma como seria apreciado o caso à luz do "modelo de direitos fundamentais sociais" de Robert Alexy.

Pois bem: seguindo o modelo de Alexy, o juiz indagaria, primeiramente, se o tratamento era exigido de forma premente pelo princípio da liberdade fática. Em uma análise inicial, a resposta seria positiva, pois a bomba infusora de insulina, ao liberar quantidades de insulina de forma paulatina ao longo do dia, torna desnecessária a aplicação de injeções múltiplas do hormônio, exigida pelo tratamento padrão, e seu uso ameniza o rigor do controle glicêmico exigido do paciente (HISSA; HISSA; BRUIN, 2001). Isso, sem dúvida nenhuma, promoveria a liberdade fática da autora, que, com o uso da bomba infusora, estaria livre da obrigação de interromper os seus afazeres diários para injetar a insulina, além de estar mais livre para definir a sua dieta alimentar. A autora teria, enfim, uma maior flexibilidade no seu estilo de vida.

Esse argumento favorável ao atendimento do pleito deveria ser contrastado com os argumentos que lhe são contrários. Nos termos da "resposta geral" dada por Alexy à questão da determinação dos direitos fundamentais sociais definitivos (ALEXY, 2008, p. 512), tais argumentos estão relacionados ao princípio da separação dos poderes, ao princípio democrático e a princípios materiais colidentes afetados na situação concreta. Caso o sacrifício desses princípios fosse compensado pelo ganho em termos de liberdade fática, o pleito deveria ser atendido.

Para verificar em que medida o princípio democrático e o princípio da separação dos poderes seriam afetados pelo deferimento do pedido de fornecimento da bomba infusora de insulina, afigurar-se-ia fundamental a análise da Lei Orçamentária Anual da entidade pública obrigada a satisfazê-lo, pois é essa lei que materializa as decisões alocativas a serem observadas pelo 
Estado ao distribuir recursos para as suas ações. A Lei Orçamentária Anual consubstancia, como nenhuma outra, o processo democrático de definição das tarefas estatais, e isso fica claro pelo próprio modo como é elaborada (art. 166 da Constituição); deixar de levá-la em consideração no momento de decidir se um direito prestacional pode ser outorgado pela via judicial é uma grave demonstração de desapreço pela atuação legítima dos mandatários eleitos pelo povo.

Tomando por base a Lei Orçamentária Anual do Município de Rancharia para 2011, ano em que o pedido foi apreciado pelo Tribunal de Justiça de São Paulo, tem-se a impressão de que a lesão ao princípio da separação dos poderes e ao princípio democrático ocasionada pelo deferimento do pedido seria mínima, desprezível até. $\mathrm{O}$ orçamento do Município ultrapassava R\$ 53 milhões (PREFEITURA MUNICIPAL DE RANCHARIA, 2012), ao passo que o custo do fornecimento da bomba infusora de insulina seria de mais ou menos US\$ 5 mil ou R\$ 10 mil (LIBERATORE JR.; DAMIANI, 2006). Logo, em um primeiro momento, seria justificável a decisão judicial em favor da autora, mesmo que o benefício trazido pelo uso da bomba infusora de insulina não fosse muito intenso, dada a pequenez do valor do orçamento estatal a ser comprometido. Então, em uma análise preliminar, as razões para o reconhecimento da existência do direito invocado (prima facie) como direito definitivo seriam prevalentes.

Entretanto, o "modelo de direitos fundamentais sociais" exige que, além do princípio da separação dos poderes e do princípio democrático, sejam tomados em conta como contra-argumentos ao reconhecimento judicial de um direito prestacional os "princípios materiais colidentes" (ALEXY, 2008, p. 512).

Ora, um dos princípios materiais que deveria ser considerado na apreciação do caso pelo Tribunal de Justiça de São Paulo é o princípio da igualdade. Seria necessário indagar se o fornecimento estatal da bomba infusora de insulina constituiria 
um benefício indevido à autora, na medida em que a privilegiaria em relação aos demais cidadãos.

Em primeiro lugar, é preciso lembrar que, no caso sob análise, havia razão suficiente para que a autora fosse tratada desigualmente em relação aos demais cidadãos, pela condição clínica que ostentava (ALEXY, 2008, p. 409); logo, o fornecimento da bomba infusora de insulina, embora muito mais caro que o tratamento da maior parte das doenças, não vulneraria necessariamente o princípio da igualdade. Porém, se havia razões suficientes para tratar a autora de forma desigual em relação aos cidadãos que não eram portadores de diabetes, não havia razões suficientes para tratá-la de forma desigual em relação aos cidadãos que, como ela, eram portadores da doença (ALEXY, 2008, p. 508). Portanto, o direito reconhecido em favor da autora deveria ser reconhecido a todos os demais portadores de diabetes.

Para ver se isso era possível seria necessário efetuar alguns cálculos. Segundo estimativas do Ministério da Saúde, no Brasil haveria 10 milhões de portadores de diabetes em 2010 (BRASIL, 2006, p. 7), quantidade que, grosso modo, corresponde a 5\% de uma população de 190 milhões (IBGE, 2010). Supondo-se que no Município de Rancharia a incidência do diabetes não destoe da taxa média de incidência no país, pode-se estimar que haveria em torno de 1.400 portadores de diabetes no território do ente público, ou seja, 5\% de uma população de 28 mil (IBGE, 2010).

Para que o princípio material da igualdade não restasse desrespeitado no caso analisado, o direito ao fornecimento da bomba de insulina reconhecido em favor da autora deveria ser extensível a todos os demais cidadãos que se encontrassem na mesma situação. Isso somente seria possível se o ente público pudesse despender $\mathrm{R} \$ 14$ milhões (mais de um quarto do orçamento municipal) só com o tratamento de diabéticos, montante necessário para pagar por um aparelho $(\mathrm{R} \$ 10 \mathrm{mil}) \mathrm{a}$ cada portador de diabetes do Município (1.400)! Mesmo que se considere que a vida útil do equipamento é de 6 anos, o impacto financeiro seria, indubitavelmente, de grande monta. 
Partindo das balizas traçadas pelo "modelo de direitos fundamentais sociais" e dos dados acima postos, pode-se dizer que o reconhecimento, em favor da autora, do direito definitivo ao fornecimento da bomba infusora de insulina implicaria ou um sacrifício intenso ao princípio da igualdade ou um sacrifício intenso aos princípios democrático e da separação dos poderes.

Uma decisão favorável à autora poderia basear-se na ideia de que o princípio da separação dos poderes seria afetado minimamente no caso individual, pois o custo do aparelho pleiteado, visto isoladamente, seria diminuto; contudo, esse raciocínio só se sustentaria caso fossem desconsiderados os direitos dos demais portadores de diabetes, em afronta manifesta ao princípio material da igualdade. O princípio da igualdade só restaria respeitado em caso de decisão favorável à autora se existissem condições de dar uma decisão igual em todas as demandas semelhantes, ou seja, se existissem condições de fornecer uma bomba de insulina a todos os portadores de diabetes; no entanto, a admissão dessa possibilidade acarretaria a aceitação de uma mutilação insuportável ao princípio da separação dos poderes, notadamente na parte em que garante a competência decisória do legislador em matéria orçamentária.

Depois dessas reflexões, pode-se prever como seria feita a operação de sopesamento neste caso concreto a partir dos parâmetros traçados por Alexy no "modelo de direitos fundamentais sociais": muito embora o princípio da liberdade fática exigisse, em certa intensidade, o reconhecimento do direito ao fornecimento da bomba de insulina, tal reconhecimento lesaria de forma séria o princípio da separação dos poderes, o princípio democrático e o princípio material da igualdade.

Diante do exposto acima, pode-se dizer que é muito provável que o Tribunal de Justiça de São Paulo decidiria em sentido contrário à autora caso se apoiasse no "modelo de direitos fundamentais sociais" proposto por Robert Alexy. Seria uma decisão menos simpática, mas que cuidaria com mais apuro dos princípios constitucionais envolvidos na apreciação da demanda. 


\section{CONCLUSÃO}

O "modelo teórico da utopia" e o "modelo de direitos fundamentais sociais" constituem tentativas de resolver a questão da efetivação dos direitos fundamentais sociais, que permanece, até o presente momento, em aberto.

O reconhecimento da inexistência de respostas para a questão não impede, contudo, a constatação da insuficiência de algumas abordagens. Dentre as maneiras de enfrentar o problema, aquela adotada pelo ministro Celso de Mello no julgamento da Petição 1.246 merece algumas críticas, por não dar a devida deferência ao princípio da separação de poderes, por exemplo. Apesar disso, fez escola e está inspirando diversos julgados Brasil afora, e é uma decisão que serve como referência para o enfrentamento das demandas relacionadas ao direito à saúde. Representa, como nenhuma outra, a consagração do "modelo teórico da utopia".

O modelo proposto por Robert Alexy é mais respeitoso dos princípios constitucionais do que o "modelo teórico da utopia", ao atentar para a necessidade de sopesar argumentos favoráveis e argumentos contrários na tarefa de determinação dos direitos fundamentais sociais definitivos. Dentre esses argumentos contrários que merecem consideração estão o princípio da separação dos poderes e o princípio democrático, além de princípios cuja potencial vulneração seja detectada na análise do caso concreto. O modelo de Alexy não garante uma prevalência automática do direito fundamental social, exigindo um cotejo entre o benefício e o prejuízo trazidos pela garantia da posição prestacional.

A adoção da perspectiva de Robert Alexy seria assaz oportuna no enfrentamento das demandas relativas ao direito à saúde. Evitaria a tomada de decisões que, por não serem universalizáveis, afrontam o princípio da igualdade. Evitaria, também, uma interferência demasiadamente saliente do Poder Judiciário na distribuição dos recursos públicos, que acaba por desrespeitar as decisões alocativas tomadas por autoridades legitimamente eleitas. 
Certamente, as lições de Alexy superam algumas das limitações do "modelo teórico da utopia". Estão longe, porém, de dar uma resposta satisfatória ao problema da definição do lugar do Poder Judiciário na outorga de direitos sociais. Dentre outras indagações que persistem, podem-se fazer as seguintes: quais critérios devem ser utilizados na operação de sopesamento para mensurar o peso dos argumentos contrários e o peso dos argumentos favoráveis ao reconhecimento do direito fundamental social definitivo? Até que ponto os princípios contrários ao reconhecimento de um direito fundamental social definitivo podem ser sacrificados? Eventuais deficiências de informação sobre os casos a serem apreciados não comprometeriam a correção da operação de sopesamento, notadamente naqueles casos que envolvem o direito à saúde, em que se faz necessário um conhecimento médico especializado? $\mathrm{O}$ debate deve prosseguir.

Abstract: Today, the Brazilian Judiciary is playing, increasingly, the role of enforcer of social rights. This position is based on a set of ideas that can be named as the "theoretical model of utopia." The "theoretical model of utopia" advocates "judicial activism" as a way to compensate for the inertia of the other powers in fulfilling the constitutional promises in the social area. A remarkable feature of this model is the absence of attention to the question of the cost of rights. The decision taken by Justice Celso de Mello in the trial of the Petição 1.246 is representative of this view, in considering that the right to health must prevail over unimportant financial interests of the government. Despite the prestige currently held by this way of treating the question of the fulfillment of social rights, it is interesting to look to this problem from the view of the "model of constitutional social rights" proposed by Robert Alexy. Robert Alexy defends the thesis that the constitutional rights norms must be seen as principles that ensure only prima facie duties; these prima facie duties only become 
definitive duties after a balancing with conflicting principles. On this basis, he draws a "general answer" to determine the existence of an entitling position guaranteed. The "model of constitutional social rights" is compatible with the Brazilian legal system, and it is possible to speculate how would be decided by the Judiciary, on this basis, a demand related to the right to health.

Keywords: Balancing. Alexy. Health. Fundamental Rights.

\section{REFERÊNCIAS}

ALEXY, Robert. Teoria dos direitos fundamentais. Tradução de Virgílio Afonso da Silva. São Paulo: Malheiros, 2008.

BARROSO, Luís Roberto. Interpretação e aplicação da constituição: fundamentos de uma dogmática constitucional transformadora. São Paulo: Saraiva, 1996.

. O direito constitucional e a efetividade de suas normas: limites e possibilidades da constituição brasileira. $4^{\mathrm{a}} \mathrm{ed}$. Rio de Janeiro: Renovar, 2000.

BONAVIDES, Paulo. Curso de direito constitucional. 10a ed. São Paulo: Malheiros, 2000.

BRASIL. Constituição da República Federativa do Brasil. São Paulo: Revista dos Tribunais, 2011.

. Ministério da Saúde. Cadernos de atenção básica nº 16: diabetes mellitus. Brasília, 2006.

. Supremo Tribunal Federal. Medida cautelar na petição. Petição 1.246 MC/SC. Requerente: Estado de Santa Catarina. Requerido: João Batista Gonçalves Cordeiro. Relator: Ministro Celso de Mello. Brasília, 13 de fevereiro de 1997. Disponível em: <http://www.stf.jus.br/portal/ diarioJustica/verDiarioProcesso.asp?numDj $=29 \&$ dataPublicacaoDj $=13 / 0$ $2 / 1997 \&$ incidente $=3724003 \&$ codCapitulo $=6 \&$ numMateria $=7 \&$ codMat eria $=2>$. Acesso em: 24 maio 2012.

. Suspensão de segurança. Agravo regimental. Saúde pública.

Direitos fundamentais sociais. Art. 196 da Constituição. Audiência 
pública. Sistema Único de Saúde -SUS. Políticas públicas. Judicialização do direito à saúde. Separação de poderes. Parâmetros para solução judicial dos casos concretos que envolvem direito à saúde. Responsabilidade solidária dos entes da Federação em matéria de saúde. Fornecimento de medicamento: Zavesca (miglustat). Fármaco registrado na ANVISA. Não comprovação de grave lesão à ordem, à economia, à saúde e à segurança públicas. Possibilidade de ocorrência de dano inverso. Agravo regimental a que se nega provimento. Agravo regimental na suspensão de tutela antecipada 175. Agravante: União. Agravado: Ministério Público Federal e outros. Relator: Ministro Gilmar Mendes. Brasília, 17 de março de 2010. Disponível em: <http://redir.stf.jus.br/paginadorpub/paginador. jsp? docTP=AC\&docID=610255>. Acesso em: 25 maio 2012.

GALDINO, Flávio. Introdução à teoria dos custos dos direitos: direitos não nascem em árvores. Rio de Janeiro: Lumen Juris, 2005.

HISSA, Miguel N.; HISSA, Ana Sofia R.; BRUIN, Veralice M. S.. Tratamento do diabetes mellitus tipo 1 com bomba de infusão subcutânea contínua de insulina e insulina lispro. Arquivos brasileiros de endocrinologia e metabologia, São Paulo, v. 45, n. 5, p. 487-493, out. 2001.

HOLMES. Stephen e SUNSTEIN, Cass. The cost of rights: why liberts depends on taxes. New Yok-London: W. W. Norton \& Company, 1999.

INSTITUTO BRASILEIRO DE GEOGRAFIA E ESTATÍSTICA: banco de dados. Disponível em: <www.ibge.gov.br>. Acesso em: 24 maio 2012.

KRELL, Andreas. Direitos sociais e controle judicial no Brasil e na Alemanha: os (des)caminhos de um direito constitucional "comparado". Porto Alegre: Sérgio Antônio Fabris, 2002.

LIBERATORE JR., Raphael del Roio; DAMIANI, Durval. Bomba de infusão de insulina em diabetes melito tipo 1 . Jornal de pediatria, v. $82, \mathrm{n}$. 4, jul. 2006.

MARTÍNEZ, Gregório Peces-Barba. Curso de derechos fundamentales: teoria general. Madrid: Universidad Carlos III/Boletín Oficial Del Estado, 1999.

MENÉNDEZ, Agustín José; ERIKSEN, Erik Oddvar (Org.). Arguing fundamental rights. Dordrecht: Springer, 2006.

PIOVESAN, Flávia. Direitos humanos e o direito constitucional internacional. 5a ed. São Paulo: Max Limonad, 2002. 
PREFEITURA MUNICIPAL DE RANCHARIA. Contas públicas.

Disponivel em: $<$ http://www.novosis.com.br/webcontas/index.jsp?estado= SP\& cliente $=15 \&$ ano=2011\&anexo=2>. Acesso em: 25 maio 2012.

SÃO PAULO (Estado). Tribunal de Justiça. Embargos infringentes.

Recurso com apoio em voto minoritário. Obrigação de fazer. Fornecimento de bomba infusora de insulina para portadora de Diabetes Mellitus. Laudo médico e perícia atestando a necessidade da bomba para o tratamento da autora. Concretização do direito à vida e à saúde, cabendo ao Estado propiciar o atendimento médico, fornecendo o insumo prescrito. É necessário que esse direito venha a ser respeitado e implementado pelo Estado, destinatário do comando Constitucional. Recurso provido. Embargos infringentes no 0000340-0000899-39.2007.8.26.0491/50000. Embargante: Municipalidade de Rancharia. Embargada: Viviane Cristina Martins Passianoto. Relator: Desembargador Magalhães Coelho. São Paulo, 29 de agosto de 2011. Disponível em: 〈http://www.tjsp.jus.br〉. Acesso em: 25 maio 2012.

SARLET, Ingo Wolfgang. A eficácia dos direitos fundamentais. 10ª ed. Porto Alegre: Livraria do Advogado, 2011.

; TIMM, Luciano Benetti (Org.). Direitos fundamentais: orçamento e "RESERVA DO POSSÍVEL". Porto Alegre: Livraria do Advogado, 2008.

TORRES, Ricardo Lobo. O direito ao mínimo existencial. Rio de Janeiro: Renovar, 2009.

TRIBUNAL DE JUSTIÇA DE MINAS GERAIS: consulta à jurisprudência. Disponível em: 〈http://www.tjmg.jus.br〉. Acesso em: 25 maio 2012.

TRIBUNAL DE JUSTIÇA DO RIO GRANDE DO SUL: pesquisa de jurisprudência. Disponível em: 〈http://www.tjrs.jus.br>. Acesso em: 25 maio de 2012.

TRIBUNAL DE JUSTIÇA DE SANTA CATARINA: jurisprudência catarinense. Disponível em: 〈http://app.tjsc.jus.br/jurisprudencia/>. Acesso em: 25 maio 2012.

TRIBUNAL DE JUSTIÇA DE SÃO PAULO: consulta de jurisprudência. Disponível em: <https://esaj.tjsp.jus.br/cjsg/consultaCompleta.do?f=1>. Acesso em: 25 maio 2012. 